\title{
MOLECULAR DOCKING STUDY BETWEEN 3 THAI MEDICINAL PLANTS COMPOUNDS AND COVID-19 THERAPEUTIC PROTEIN TARGETS: SARS-COV-2 MAIN PROTEASE, ACE-2, AND \\ PAK-1
}

\section{SAFIRA CANDRA ASIH ${ }^{1}$, RAFIDHA IRDIANI ${ }^{1}$, MUHAMAD SAHLAN ${ }^{1,2}$, MOHAMMAD NASIKIN $^{1}$}

\author{
${ }^{1}$ Department of Chemical Engineering, Faculty of Engineering, Universitas Indonesia, Kampus UI Depok, 16424, West Java, \\ Indonesia, ${ }^{2}$ Research Center for Biomedical Engineering, Faculty of Engineering, Universitas Indonesia, Kampus UI Depok, 16424, West \\ Java, Indonesia \\ Email: mnasikin@che.ui.ac.id
}

Received: 30 Aug 2020, Revised and Accepted: 07 Oct 2020

\begin{abstract}
Objective: The present study aimed to evaluate those 3 compounds among 122 Thai natural products by using a molecular docking approach to inhibit Main Protease (Mpro) of SARS-CoV-2 (PDB code: 6Y2F), Angiotensin Converting Enzyme (ACE)-2 (PDB code: 1R4L), and PAK-1 kinase (PDB code: 5DEW)

Methods: The evaluation was performed on the docking scores calculated using AutoDock Vina as a docking engine and interaction profile analysis through 2-dimensional visualization using LigPlot+. The determination of the docking score was done by selecting the conformation of the ligand
\end{abstract} that has the lowest binding free energy (best pose).

Result: The results of this study indicate that overall, Panduratin A has the best affinity in inhibiting the main protease of SARS-CoV-2, ACE-2, and PAK-1 compared to other compounds.

Conclusion: The three thai medicinal plants compound has the potential to be developed as specific therapeutic agents against COVID-19.

Keywords: Thai Medicinal plants, Mpro, ACE-2, PAK-1, COVID-19, SARS-CoV-2

(C) 2021 The Authors. Published by Innovare Academic Sciences Pvt Ltd. This is an open access article under the CC BYlicense (http://creativecommons.org/licenses/by/4.0/) DOI: http://dx.doi.org/10.22159/ijap.2021.v13s2.08 Journal homepage: https://innovareacademics.in/journals/index.php/ijap

\section{INTRODUCTION}

In late December 2019, it was noticed that several people in Wuhan city of Hubei Province, China, were suffering from SARS-like pneumonia. Later, the human to human transmission of 2019-nCoV was confirmed. By October $1^{\text {st }}$, the viruses have been spread into 213 countries with 33,842,281 confirmed cases and 1,010,634 confirmed deaths [1]. It means that COVID-19 has efficient humanto-human transmission leading to its widespread outbreaks in many countries around the world $[2,3]$.

Until now, there is no FDA-approved or specific treatment for COVID-19 infection. Clinical guidance of the World Health Organization (WHO) and Centers for Disease and Control Prevention (CDC) only include prompt supportive care like oxygen therapy, fluid management, empiric antimicrobials (in case of sepsis), and others $[1,4]$. Investigational agents reported some potential therapy for COVID-19 such as remdesivir or chloroquinone and combined protease inhibitor lopinavir-ritonavir, which are previously used to treat against SARS and MERS-CoV but their efficacy is still unclear and needs further evaluation [5-7]. On the other hand, the vaccine candidates for COVID-19 are still in development and takes about 12-18 mo to release it into the market. However, finding a cure and specific treatments is being a great help for the international community. In the current crisis, to achieve a fast and reliable drug, we decided to do a virtual screening procedure via molecular docking to find the potential molecule inhibitors to combat the COVID-19 outbreak.

SARS-CoV-2 is known to belong to the Coronaviridae (CoV) family. This brings up the opportunity to discover COVID-19 potential drugs based on prior research regarding other types of coronaviruses. Previous research has shown that Coronavirus protease is one of the most promising protein therapeutic targets to treat viral infection [8]. The enzyme cleaves polyproteins translated from viral RNA into 12 smaller proteins that participate in viral replication [9]. Thus, viral replication can be blocked by inhibiting the activity of this enzyme [10]. Furthermore, currently, researchers from around the world are lending their expertise to develop drugs targeting this protein. An experiment by Zhang et al. (2020) exhibited that a peptidomimetic $\alpha$-ketoamide compound, namely $13 \mathrm{~b}$, is effective in inhibiting the replication of SARS-CoV-2 in human Calu3 lung cells. The structure of SARS-CoV-2 protease bound with $13 \mathrm{~b}$ has been crystallized and available under the protein data bank (PDB) ID 6Y2F. This can be used for further computational study for COVID19 drug discovery.

Another study conducted by Yan et al. in 2020 confirmed that the new coronavirus (SARS-CoV-2) has the same cellular receptors as SARS coronavirus (SARS-CoV), namely angiotensin-converting enzyme 2 (ACE-2) [11]. The activity of this protein is known to be inhibited by a potent inhibitor, namely MLN-4760. MLN-4760 can alter the conformation of ACE-2 that may advantageous to prevent binding with SARS-CoV-2 [12]. The structure of ACE-2 bound with MLN-4760 is available under the PDB ID 1R4L.

Another protein target that can be used to find the potential new compound to treat SARS-CoV-2 is PAK-1. PAK1 is the major "pathogenic" kinase whose abnormal activation is responsible for a wide variety of diseases such as cancers, inflammation, viral infection, malaria, immuno-suppression, aging, and so on [13]. In 2005, Chloroquine (CQ) show to suppress SARS/coronavirus infection in cell culture with IC50 around 1uM [14], although the precise molecular mechanism underlying its anti-viral activity remains unknown recently. In 2016, a Korean team found that CQ up-regulates p21 (a CDK inhibitor) whose expression is suppressed by PAK1 [13]. More recently, a tumor-suppressing phosphate called PTEN, which inactivates PAK1, was shown to suppress the coronavirus-induced LLC2-dependent fibrosis [15]. Furthermore, expression of LLC2 depends on the coronavirus receptor (ACE2)induced CK2/RAS-PAK1-RAF-AP1 signaling pathway [16]. These observations altogether clearly indicate the PAK1-dependency of coronaviral pathogenesis and strongly suggest, if not proven clinically yet, that PAK1-blockers, in general, could be useful for the treatment of current pandemic COVID-19 infection. 
On the other hand, the latest research conducted by Kanjanasirirat et al. in 2020 [17] found the 3 most potent compounds as anti-SARSCoV-2 agents among 122 Thai natural products using fluorescencebased SARS-CoV-2 nucleoprotein detection in Vero E6 cells coupled with plaque reduction assay. These three compounds consist of andrographolide, 6-gingerol, and pandurotin A. The present study aimed to evaluate those 3 compounds by using a molecular docking approach to inhibit Main Protease (Mpro) of SARS-CoV-2 (PDB code: 6Y2F), Angiotensin Converting Enzyme (ACE)-2 (PDB code: 1R4L), and PAK-1 kinase (PDB code: 5DEW).

\section{MATERIALS AND METHODS}

\section{Hardware}

Docking simulation between test compounds and SARS-CoV-2 main protease and ACE-2 were performed within a laptop with specifications of an Intel ${ }^{\circledR}$ Core $^{\mathrm{TM}}$ i7-8550U @1.80 GHz processor, 8 GB of RAM, the Windows 10 Home Single Language 64-bit operating system, and an Intel ${ }^{\circledR}$ UHD Graphics 620 graphics processing unit. Meanwhile, docking simulation between test compounds and PAK-1 was done in a laptop with specifications of a processor (CPU) Intel@ Core $^{\mathrm{TM}}$ i7-7500U @ 2.70 GHz, graphics processing unit (GPU) Nvidia® GeForce 940 MX and 8 GB RAM with Windows 10 Home Single Language 64-bit was used.

\section{Software}

The software used in this research are MarvinSketch (ChemAxon), AutoDockTools 1.5.6 (The Scripps Research Institute, Amerika), AutoDock Vina (The Scripps Research Institute, Amerika), Notepad++(GNU General Public License), Ligplot+(European Bioinformatics Institute, United Kingdom), VMD (University of Illinois, Urbana Champaign), and PyMOL 3D Quad Buffer (Schrödinger, inc.)

\section{Preparation of receptors}

The crystal structures of SARS-CoV-2 Main Protease (Protein Data Bank [PDB] Code: 6Y2F) were downloaded from the Protein Data Bank (RCSB PDB, http://www. rcsb. org). In this structure, SARS$\mathrm{CoV}-2$ Main Protease is co-crystalized with inhibitor $13 \mathrm{~b}$. The second receptors, crystal structures of ACE-2 (Protein Data Bank [PDB] Code: 1R4L) was downloaded from the Protein Data Bank (RCSB PDB, http://www.rcsb.org). In this structure, ACE-2 is co-crystalized with inhibitor MLN4760. The third receptor that are going to use in this study, crystal structures of PAK-1 (Protein Data Bank [PDB] Code: 5DEW) was downloaded from the Protein Data Bank (RCSB PDB, http://www.rcsb.org). In this structure, PAK1 is co-crystalized with the selective inhibitor G-5555. Each receptor file is then loaded to Visual Molecular Dynamics (VMD) (University of Illinois, Urbana Champaign) to separate the protein from its native ligand to facilitate the docking studies with molecule candidates. Next, the separated protein was submitted to AutoDock Tools 1.5.6 for pdbqt file preparation. The protein refinement involved the addition of polar hydrogen atoms and merging non-polar hydrogen.

\section{Preparation of ligands}

All inhibitor candidates from the Thailand medicinal plants compounds, here termed as the ligand, were constructed in 2dimensional view, energy minimized, and converted to the 3dimensional structure using Marvin Sketch program (ChemAxon, Budapest, Hungary) then finished by saving all as PDB (protein data bank) format file for docking simulations. The information about all inhibitor candidates such as chemical structure and formula were retrieved from the PubChem database (https://pubchem. ncbi.nlm.nih.gov/) and tabulated in table 1.

Table 1: Details of the ligands

\begin{tabular}{|c|c|c|c|}
\hline No. & Compound & Chemical formula & Structure \\
\hline 1 & Andrographolide & $\mathrm{C}_{20} \mathrm{H}_{30} \mathrm{O}_{5}$ & . \\
\hline 2 & 6-Gingerol & $\mathrm{C}_{17} \mathrm{H}_{26} \mathrm{O}_{4}$ & \\
\hline 3 & Panduratin A & $\mathrm{C}_{26} \mathrm{H}_{30} \mathrm{O} 4$ & \\
\hline
\end{tabular}




\section{Validation of molecular docking method}

AutoDock Vina is selected to be the docking program used in this study. As the program requires a specific "search space" in the coordinate system of the receptor, it is required to do the validation procedure to find out the size and the coordinate of the grid box that will be used for molecular docking of test compounds. The native ligand bound to the selected receptor (SARS-CoV-2 Main Protease with inhibitor 13b, ACE-2 with inhibitor MLN-4760, and PAK-1 with inhibitor G-5555), was extracted and redocked in the binding pocket. Thereafter, it was found that the best grid structure and coordinates are tabulated in table 2 . The genetic algorithm parameters were set to default which population size is 150 , the maximum number of the evaluation set to medium, the maximum number of generations is 27,000 and of top individuals that automatically survive is 1 , and the rate of gene mutation and crossover were 0.02 and 0.8 respectively. The rest of the docking parameters were set to the default setting of the program. Here to verify the accuracy, ligand out from redocking was evaluated in terms of the root mean square deviation (RMSD) between the docked pose and the experimentally determined pose The prediction was considered successful as the RMSD value obtained is less than $2.0 \AA$ [18].

\section{Docking simulation}

Molecular docking simulation was carried out with AutoDock Vina (The Scripps Research Institute, La Jolla, CA, USA). As a newly developed program, AutoDock Vina significantly improves the accuracy of the binding mode predictions and achieves approximately two orders of magnitude speed-up compared to AutoDock 4 [19]. The grid box dimension and coordinates are based on the parameter optimization for each receptor-native ligand pairs. The docking study was performed using the ligands listed in table 1 against 3 receptors: SARS-CoV-2 Main Protease, ACE-2, and PAK-1.

\section{Analysis and visualization of docked pose}

After docking simulation, poses with the highest negative binding free energy $(\mathrm{kcal} / \mathrm{mol}$ ) were selected as the best pose for corresponding ligand binding in the case of AutoDock Vina. The best-predicted poses were visualized and analyzed by PyMol (Schrödinger, Inc., New York, NY, USA). While the schematic representation of ligand and interacted residues inside the binding site of the receptor was then generated by LigPlot+(European Bioinformatics Institute, United Kingdom) program for a two-dimensional view [20].

\section{RESULTS AND DISCUSSION}

\section{Validation of molecular docking results}

The results of RMSD value from the redocking process fulfill the requirements to have a value of less than $2.0 \AA$ and are tabulated in table 2 .

Molecular interaction of Thai medicinal compounds and SARSCoV-2 main protease

Docking simulation was performed to generate two results, which are the docking score and the most stable ligand pose. The docking score is generated from an empirical calculation that considers hydrophobic interactions and hydrogen bonding [19]. The docking score represents binding affinity, and it is inversely proportional to the binding stability [21]. In the meantime, the most stable ligand pose further will give the information of which amino acid interacts with the ligand spontaneously. By comparing the amino acid interacting with the potent inhibitor and with the test compound, the potency of a test compound to have the ability to inhibit the protein with the same pathway as the potent inhibitor may be predicted. The docking score between SARS-CoV-2 main protease and test compounds are available in fig. 1.

Table 2: Parameter optimization results

\begin{tabular}{|c|c|c|c|c|}
\hline No. & Receptor and native ligand pairs & Grid box area & Coordinates & RMSD \\
\hline 1 & SARS-CoV-2 Main Protease with inhibitor $13 \mathrm{~b}$ & $\begin{array}{l}x=25 \AA \\
y=25 \AA \\
z=25 \AA\end{array}$ & $\begin{array}{l}x=11.476 \\
y=-1.395 \\
z=20.745\end{array}$ & 1.597 \\
\hline 2 & ACE-2 with inhibitor MLN4760 & $\begin{array}{l}x=25 \AA \\
y=25 \AA \\
z=25 \AA\end{array}$ & $\begin{array}{l}x=40.199 \\
y=-6.024 \\
z=29.006\end{array}$ & 1.346 \\
\hline 3 & PAK-1 with inhibitor G-5555 & $\begin{array}{l}x=25 \AA \\
y=25 \AA \\
z=25 \AA\end{array}$ & $\begin{array}{l}x=19.295 \\
y=-13.282 \\
z=11.782\end{array}$ & 1.253 \\
\hline
\end{tabular}

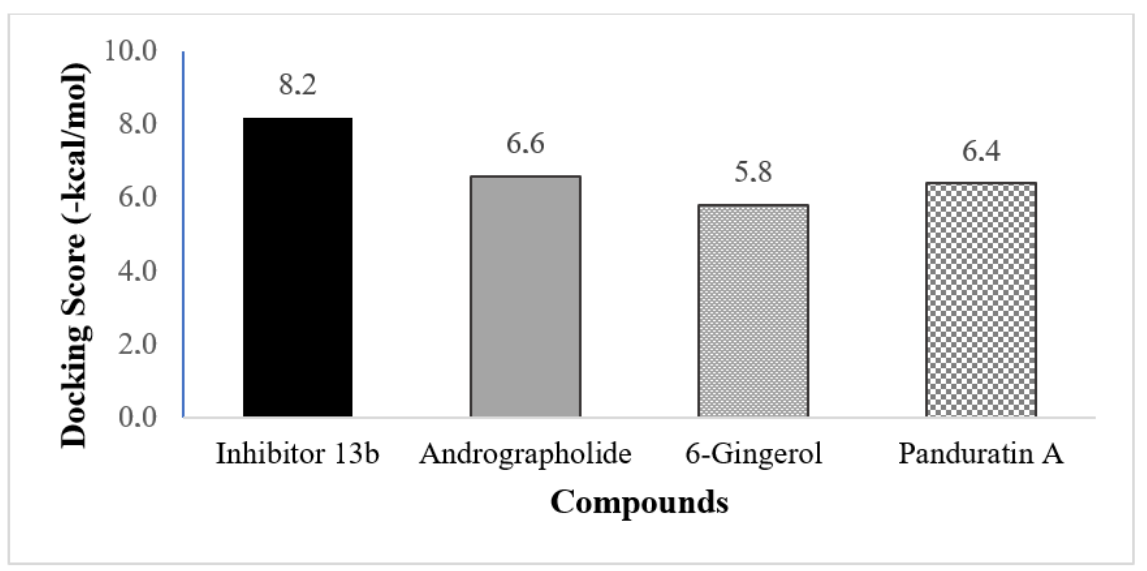

Fig. 1: Docking score between SARS-CoV-2 main protease and test compounds

Based on the docking simulation, $13 \mathrm{~b}$ bound to the main protease with a docking score of $-8.2 \mathrm{kcal} / \mathrm{mol}$, while andrographolide, 6gingerol and panduratin A generated a docking score with the value of $-6.6,-5.8$ and $-6.4 \mathrm{kcal} / \mathrm{mol}$ respectively. Although none of the test compounds generated a docking score that is less than the docking score of native ligand, the docking score of each compound is all negative. This indicated that all test compounds can bind with the protein. Andrographolide has the lowest docking score overall. 
The interaction profile between SARS-CoV-2 main protease and inhibitor 13b, andrographolide, 6-gingerol, and panduratin A several are attached in fig. 2. The molecular interaction between SARS-CoV2 main protease and inhibitor 13b was firstly analyzed. According to the result, Inhibitor 13b generated hydrogen bonds with five amino acids, those are His ${ }^{41}, \mathrm{Gly}^{143}$, Ser ${ }^{144}$, Cys ${ }^{145}$, and Glu ${ }^{166}$. His $^{41}$ and Cys ${ }^{145}$ are known as the catalytic sites of SARS-CoV-2 main protease [22] The shortest interatomic distance between inhibitor $13 \mathrm{~b}$ and His ${ }^{41}$ and $\mathrm{Cys}^{145}$ are 3.03 and $3.27 \AA$ respectively. Interaction with these amino acids is important to inhibit the activity of the enzyme.
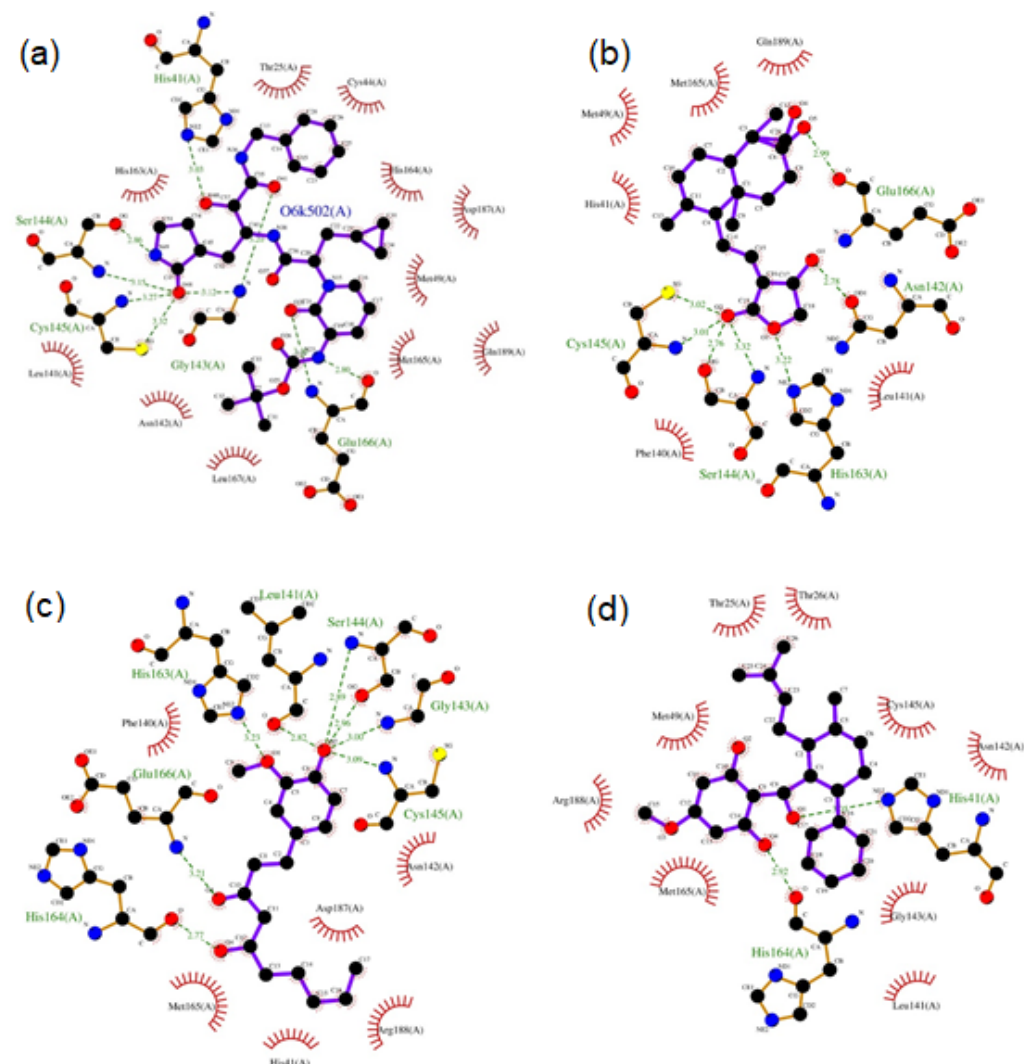

Fig. 2: Docking score between SARS-CoV-2 main protease and test compounds, (a) inhibitor 13b, (b) andrographolide, (c) 6-gingerol, (d) panduratin $A$. The purple lines denote the ligand structure, whereas the brown lines denote the structure of amino acid residues. The molecular interactions are reflected as dashed lines and arcs. The green dashed lines between atoms represent hydrogen bonds, and the numbers above these lines indicate the length of the bond. Meanwhile, the arcs with spokes radiating toward the ligand atoms represent hydrophobic interactions. The atoms involved in hydrophobic interactions are indicated by the presence of spokes radiating back [20]

The interaction profile between SARS-CoV-2 main protease and each test compounds was then analyzed. Andrographolide formed a hydrogen bond with Cys ${ }^{145}$ and interacted hydrophobically with His $^{41}$. The interatomic distance between the compound and Cys ${ }^{145}$ is $3.01 \AA$ A This indicated that andrographolide may bind stronger to Cys ${ }^{145}$ compared to inhibitor 13b. In the meantime, 6-gingerol also formed a hydrogen bond with Cys ${ }^{145}$ and interacted hydrophobically with $\mathrm{His}^{41}$. Same as andrographolide, 6-gingerol also bound stronger to Cys ${ }^{145}$ compared to inhibitor $13 \mathrm{~b}$, with an interatomic distance of 3.09 A. Lastly, for panduratin A, it is shown that this compound formed a hydrogen bond with His ${ }^{41}$ and interacted hydrophobically with Cys $^{145}$. The interatomic distance of $3.05 \AA$ between the compound and $\mathrm{His}^{41}$ indicated that this compound may bind stronger to His ${ }^{41}$ compared to inhibitor $13 \mathrm{~b}$. Meanwhile, the hydrophobic interaction with catalytic sites shows that the compound may still have the potency to inhibit the activity of the enzyme. However, the binding affinity may not as strong as hydrogen bonds.

Furthermore, the binding similarity between the interaction profile of SARS-CoV-2 main protease and each test compounds compared to the interaction profile of SARS-CoV-2 main protease and inhibitor $13 \mathrm{~b}$ was calculated. It was done to become another consideration in analyzing the potency of the test compounds to become SARS-CoV-2 main protease inhibitors. Andrographolide, 6-gingerol, and panduratin A bound to SARS-CoV-2 main protease with the similarities of $63 \%, 69 \%$, and $50 \%$ respectively. Table 3 summarizes the interaction profile between SARS-CoV-2 main protease and each test compound.

Table 3: Interaction profile between SARS-cov-2 main protease and test ligands

\begin{tabular}{|c|c|c|c|c|}
\hline Compound & Hydrophobic interactions & Hydrogen bonds & $\begin{array}{l}\text { Number of } \\
\text { interaction }\end{array}$ & $\begin{array}{l}\text { Binding } \\
\text { similarity }\end{array}$ \\
\hline Inhibitor $13 \mathrm{~b}$ & $\begin{array}{l}\text { Thr }^{25}, \text { Cys }^{44}, \text { Met }^{49}, \text { Leu }^{141}, \text { Asn }^{142}, \text { His }^{163} \\
\text { His }^{164}, \text { Met }^{165}, \text { Leu }^{167}, \text { Asp }^{187}, \text { Gln }^{189}\end{array}$ & His $^{41}$, Gly ${ }^{143}$, Ser $^{144}$, Cys $^{145}$, Glu$^{166}$ & 16 & $100 \%$ \\
\hline Andrographolide & His $^{41}$, Met $^{49}$, Phe $^{140}$, Leu $^{141}$, Met $^{165}$, Gln $^{189}$ & Asn $^{142}$, Ser $^{144}$, Cys $^{145}$, His $^{163}$, Glu $^{166}$ & 11 & $63 \%$ \\
\hline 6-Gingerol & His $^{41}$, Phe $^{140}$, Asn $^{142}$, Met $^{165}$, Asp $^{187}, \operatorname{Arg}^{188}$ & $\begin{array}{l}\text { Leu }^{141}, \text { Gly }^{143}, \text { Ser }^{144}, \text { Cys }^{145}, \text { His }^{163} \text {, } \\
\text { His }^{164}, \text { Glu}^{166}\end{array}$ & 13 & $69 \%$ \\
\hline Panduratin A & 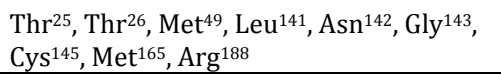 & His $^{41}$, His $^{164}$ & 11 & $50 \%$ \\
\hline
\end{tabular}




\section{Molecular interaction of Thai medicinal compounds and ACE-2}

The docking score between ACE-2 and test compounds are available in fig. 3. Based on the docking simulation, inhibitor MLN-4760 bound to ACE-2 with a docking score of $-9.2 \mathrm{kcal} / \mathrm{mol}$. Meanwhile, andrographolide, 6-gingerol, and panduratin A generated a docking score with a value of $-8.5,-7.3$, and $-9.6 \mathrm{kcal} / \mathrm{mol}$ respectively. The negative value of the docking score generated by all test compounds indicated that all test compounds can bind with the protein Panduratin A has the lowest docking score above all. The value is also lower compared to inhibitor MLN-4760. It may indicate that panduratin A can bind stronger than inhibitor MLN-4760.

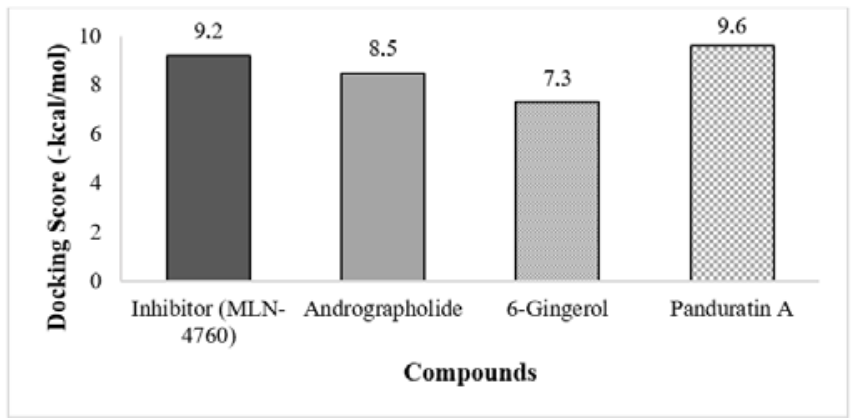

Fig. 3: Docking score between ACE-2 and test compounds

The interaction profile between ACE- 2 and inhibitor MLN-4760, andrographolide, 6-gingerol, and panduratin A several are available in fig. 4. Unlike SARS-CoV-2 main protease, the key residues to inhibit the activity of ACE-2 is relatively unknown. Therefore, the hydrogen bonds between ACE-2 and MLN-4760 informed in the crystallographer report was used as a basis for analysis. The amino acids are $\operatorname{Arg}^{273}$, $\mathrm{His}^{345}$, $\mathrm{Pro}^{346}, \mathrm{Thr}^{371}$, and $\mathrm{His}^{505}$ [12]. According to the result, andrographolide interacted hydrophobically with $\mathrm{His}^{345}$ and $\mathrm{Pro}^{346}$. There is no interaction with the rest of the expected key residues. Meanwhile, 6-gingerol formed hydrogen bonding with one expected key residue, which is $\mathrm{His}^{345}$. The interatomic distance is known to be $3.03 \AA$ and is greater than the bond that exists in inhibitor MLN-4760. In the meantime, panduratin A formed hydrogen bonds with Arg273 and $\mathrm{Thr}^{371}$ and interacted hydrophobically with $\mathrm{His}^{345}$. The interatomic distance between panduratin A and Arg273 and Thr371are 3.13 and 2.75 $\AA ̊$ respectively. The hydrogen bond between panduratin A and Arg273 is weaker compared to in MLN-4760. However, the hydrogen bond between panduratin $\mathrm{A}$ and $\mathrm{Thr}^{371}$ is known to be stronger compared to the interatomic distance between MLN-4760 and Thr ${ }^{371}$ attachedin the crystallographer report, which is $3.0 \AA$.

Furthermore, the binding similarity between the interaction profile of ACE- 2 and each test compound compared to the interaction profile of ACE-2 and inhibitor MLN-4760 was also calculated to become further consideration. Andrographolide, 6-gingerol, and panduratin A bound to ACE- 2 with the similarities of $15 \%, 8 \%$, and $46 \%$ respectively. Table 4 summarizes the interaction profile between ACE-2 and each test compound.
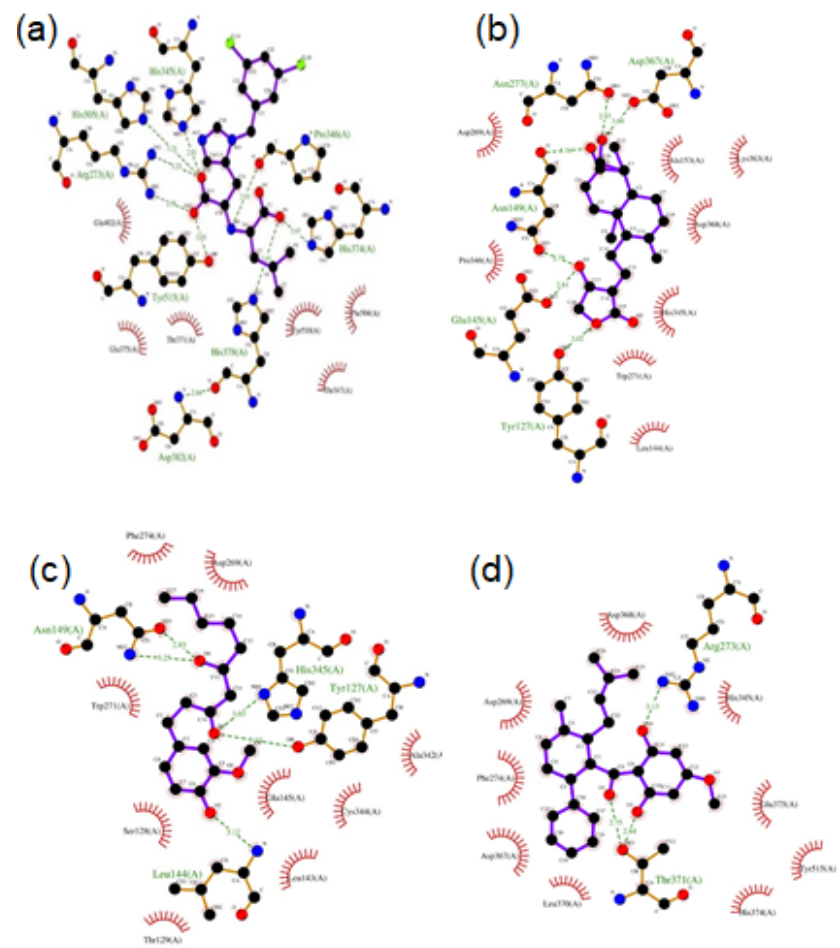

Fig. 4: Docking score between ACE-2 and test compounds, (a) inhibitor 13b, (b) andrographolide, (c) 6-gingerol, (d) panduratin A. The purple lines denote the ligand structure, whereas the brown lines denote the structure of amino acid residues. The molecular interactions are reflected as dashed lines and arcs. The green dashed lines between atoms represent hydrogen bonds, and the numbers above these lines indicate the length of the bond. Meanwhile, the arcs with spokes radiating toward the ligand atoms represent hydrophobic interactions. The atoms involved in hydrophobic interactions are indicated by the presence of spokes radiating back [20] 
Table 4: Interaction profile between ACE-2 and test ligands

\begin{tabular}{|c|c|c|c|c|}
\hline Compound & Hydrophobic interactions & Hydrogen bonds & $\begin{array}{l}\text { Number of } \\
\text { interaction }\end{array}$ & $\begin{array}{l}\text { Binding } \\
\text { similarity }\end{array}$ \\
\hline Inhibitor MLN-4760 & $\mathrm{Thr}^{347}, \mathrm{Glu}^{375}, \mathrm{Thr}^{371}, \mathrm{Glu}^{402}, \mathrm{Phe}^{504}, \mathrm{Tyr}^{510}$ & $\begin{array}{l}\text { Arg }^{273}, \text { His }^{345}, \text { Pro }^{346}, \text { His }^{374}, \text { His }^{378} \text {, } \\
\text { His }^{505}, \text { Tyr }^{515}\end{array}$ & 13 & $100 \%$ \\
\hline Andrographolide & $\begin{array}{l}\text { Leu }^{144}, \text { Ala }^{153}, \text { Asp }^{269}, \text { Trp }^{271}, \text { His }^{345}, \text { Pro }^{346} \\
\text { Lys }^{363}, \text { Asp }^{368}\end{array}$ & Tyr $^{127}$, Glu $^{145}$, Asn $^{149}$, Asn $^{277}$, Asp $^{367}$ & 13 & $15 \%$ \\
\hline 6-Gingerol & $\begin{array}{l}\text { Ser } 128, \text { Thrr }^{129}, \text { Leu }^{143}, \text { Glu }^{145}, \text { Asp }^{269}, \text { Trp }^{271} \text {, } \\
\text { Phe }^{274}, \text { Ala }^{342}, \text { Cys }^{344} \text {. }\end{array}$ & Tyr $^{127}$, Leu $^{144}$, Asn $^{149}$, His $^{345}$ & 13 & $8 \%$ \\
\hline Panduratin A & $\begin{array}{l}\text { Asp }^{269}, \text { Phe }^{274}, \text { His }^{345}, \text { Asp }^{367}, \text { Asp }^{368}, \text { Leu }^{370} \\
\text { His }^{374}, \text { Glu }^{375}, \text { Tyr }^{515}\end{array}$ & $\operatorname{Arg}^{273}$, Thr $^{371}$ & 11 & $46 \%$ \\
\hline
\end{tabular}

\section{Molecular interaction of Thai medicinal compounds and PAK-1}

The docking score between PAK-1 and test compounds are available in fig. 5. Based on the docking simulation, inhibitor G-5555 bound to PAK-1 with a docking score of $-9.5 \mathrm{kcal} / \mathrm{mol}$. Meanwhile, andrographolide, 6-gingerol, and panduratin A generated a docking score with a value of- $7.5,-6.2$, and $-7.4 \mathrm{kcal} / \mathrm{mol}$ respectively. The negative value of the docking score generated by all test compounds indicated that all test compounds can bind with the protein. Panduratin A has the lowest docking score above all test compounds.

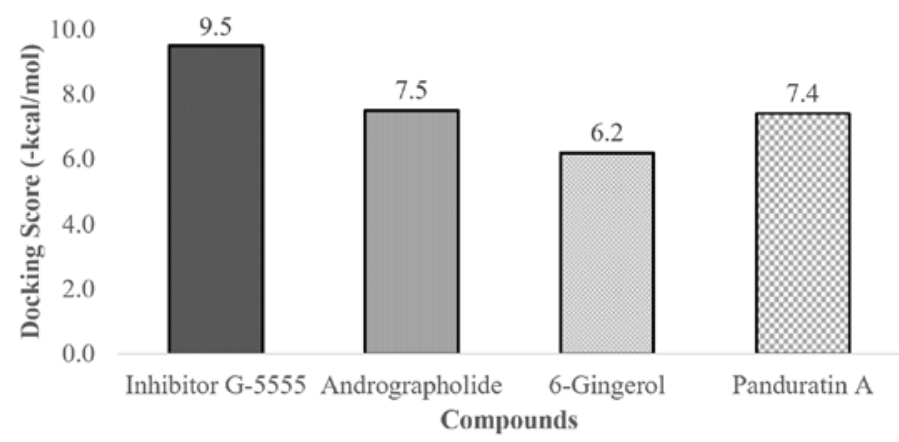

Fig. 5: Docking score between PAK-1 and test compounds
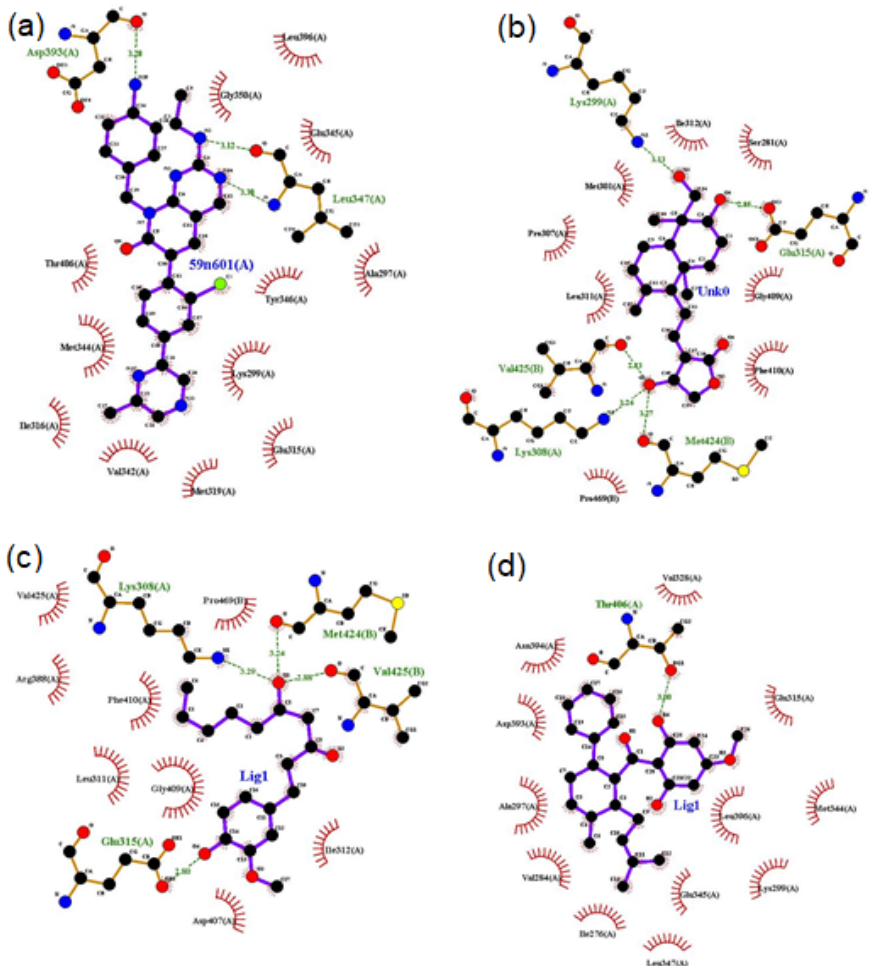

Fig. 6: Docking score between PAK-1 and test compounds, (a) inhibitor G-5555, (b) andrographolide, (c) 6-gingerol, (d) panduratin A. The purple lines denote the ligand structure, whereas the brown lines denote the structure of amino acid residues. The molecular interactions are reflected as dashed lines and arcs. The green dashed lines between atoms represent hydrogen bonds, and the numbers above these lines indicate the length of the bond. Meanwhile, the arcs with spokes radiating toward the ligand atoms represent hydrophobic interactions. The atoms involved in hydrophobic interactions are indicated by the presence of spokes radiating back [20] 
The interaction profile between PAK-1 and inhibitor G-5555, andrographolide, 6-gingerol, and panduratin A several are available in fig. 6. Unlike SARS-CoV-2 main protease, the key residues to inhibit the activity of PAK-1 is relatively unknown. Therefore, the hydrogen bonds between PAK-1 and inhibitor G-5555 informed in the crystallographer report was used as a basis for analysis. According to the result, andrographolide interacted hydrophobically with $\mathrm{Glu}^{315}$ and $\mathrm{Lys}^{299}$. There is no interaction with the rest of the expected key residues. Meanwhile, 6-gingerol formed hydrophobic and hydrogen bonding with one expected key residue, which is
$\mathrm{Glu}^{315}$. In the meantime, panduratin A formed hydrogen bonds with $\mathrm{Thr}^{406}$ and interacted hydrophobically with $\mathrm{Glu}^{345}$, $\mathrm{Lys}^{299}$, $\mathrm{Leu}^{396}$, $\mathrm{Met}^{344}, \mathrm{Asp}^{393}$, Glu ${ }^{315}$, and $\mathrm{Thr}^{406}$

Furthermore, the binding similarity between the interaction profile of PAK-1 and each test compound compared to the interaction profile of PAK-1 and inhibitor G-5555 was also calculated to become further consideration. Andrographolide, 6-gingerol, and panduratin A bound to PAK-1 with the similarities of $14.3 \%, 7.1 \%$, and $50 \%$ respectively. Table 5 summarizes the interaction profile between PAK-1 and each test compound.

Table 5: Interaction profile between PAK-1 and test ligands

\begin{tabular}{|c|c|c|c|c|}
\hline Compound & Hydrophobic interactions & Hydrogen bonds & $\begin{array}{l}\text { Number of } \\
\text { interaction }\end{array}$ & Binding similarity \\
\hline Inhibitor G-5555 & $\begin{array}{l}\text { Ile }^{316}, \text { Val }^{342}, \text { Met }^{319}, \text { Glu }^{315}, \text { Lys }^{299}, \text { Met }^{344}, \text { Tyr }^{346} \\
\text { Thrr }^{406}, \text { Ala }^{297}, \text { Leu }^{347}, \text { Glu }^{345}, \text { Glys }^{350}, \text { Asp }^{393}, \text { Leu }^{396}\end{array}$ & $\mathrm{Leu}^{347}, \mathrm{Asp}^{393}$ & 14 & $100 \%$ \\
\hline Andrographolide & $\begin{array}{l}\text { Pro } \\
\text { Pro }^{307}, \text { Met }^{424}, \text { Lys }^{315}, \text { Met }^{301}, \text { Ser }^{281}, \text { Ile }^{312}, \text { Lys }^{299}\end{array}$ & $\begin{array}{l}\text { Met }^{424}, \text { Lys }^{308}, \text { Val }^{425} \\
\text { Glu }^{315}, \text { Lys }^{299}\end{array}$ & 13 & $14.3 \%$ \\
\hline 6-Gingerol & $\begin{array}{l}\text { Asp }^{407}, \mathrm{Ile}^{312}, \mathrm{Glu}^{315}, \mathrm{Gly}^{409}, \mathrm{Leu}^{311}, \mathrm{Phe}^{410}, \mathrm{Arg}^{388} \text {, } \\
\text { Val }^{425 \mathrm{~b}}, \mathrm{Met}^{424}, \mathrm{Pro}^{469}, \mathrm{Lys}^{308}, \mathrm{Val}^{425 \mathrm{a}}\end{array}$ & $\begin{array}{l}\text { Lys }^{308}, \text { Met }^{424}, \text { Val }^{425 b} \text {, } \\
\text { Glu }^{315}\end{array}$ & 12 & $7.1 \%$ \\
\hline Panduratin A & $\begin{array}{l}\text { Leu }^{347}, \mathrm{Ile}^{276}, \mathrm{Glu}^{345}, \mathrm{Lys}^{299}, \mathrm{Val}^{284}, \mathrm{Ala}^{297}, \mathrm{Leu}^{396}, \\
\mathrm{Met}^{344}, \mathrm{Asp}^{393}, \mathrm{Glu}^{315}, \mathrm{Asn}^{394}, \mathrm{Val}^{328}, \mathrm{Thr}^{406}\end{array}$ & Thr ${ }^{406}$ & 13 & $50 \%$ \\
\hline
\end{tabular}

This study provides preliminary information about the most potent inhibitor of the protein Main Protease Sars-CoV-2, ACE-2, and PAK-1 among 3 Thailand medicinal plant compounds. The suggested compound, hence, can be used as a reference to generate a lead compound for SARS-CoV-2 drug discovery in the future study. These residues may be the key to discover a new drug in the future or to develop the existing ones through modification of chemical structures. Docking study is a very useful method to predict the interaction between a ligand and receptor, however, it still has limitations due to the simplification of the method. Therefore, refinement of the docking results can be done further by approaching molecular dynamic simulation to give a more accurate binding prediction.

\section{CONCLUSION}

Despite comparable binding affinity obtained by anti-SARS-CoV-2 biomarkers in Thailand medicinal compounds propolis toward main protease SARS-CoV-2, ACE-2, and PAK-1, this research suggested that panduratin $\mathrm{A}$ is the most potent inhibitor for the 3 biomarkers. In the whole study, it can be concluded that panduratin $A$ is a promising candidiasis alternative that can be used as a reference to generate a lead compound for anti-SARS-CoV-2 drug discovery.

\section{ACKNOWLEDGMENT}

We are gratefully acknowledging the financial support from the Directorate of Higher Education

Ministry of Research Technology and High Education, Republic of Indonesia through the "PMDSU Grant" Research Grant 2020.

\section{FUNDING}

Ministry of Research Technology and High Education, Republic of Indonesia has financial support in the study.

\section{AUTHORS CONTRIBUTIONS}

All the authors have contributed equally.

\section{CONFLICT OF INTERESTS}

There is no conflict of interest.

\section{REFERENCES}

1. Organization WH. WHO Coronavirus Disease (COVID-19) Dashboard; 2020. Available from: https://covid19.who.int/. [Last accessed on 15 Aug 2020].

2. Munster VJ, Koopmans M, van Doremalen N, van Riel D, de Wit E. A novel coronavirus emerging in China-key questions for impact assessment. N England J Med 2020;382:692-4.
3. Malik YS, Kumar N, Sircar S, Kaushik R, Bhat S, Dhama K, et al. Coronavirus disease pandemic (COVID-19): challenges and a global perspective. Pathogens 2020;9:519.

4. Bansal M, Walia MK. The covid 19-an overview on epidemiology, symptoms, prevention, management, treatment and role of health workers. Int J Appl Pharm 2020;12:36-41.

5. Wang M, Cao R, Zhang L, Yang X, Liu J, Xu M, et al. Remdesivir and chloroquine effectively inhibit the recently emerged novel coronavirus (2019-nCoV) in vitro. Cell Res 2020;30:269-71.

6. Lim J, Jeon S, Shin HY, Kim MJ, Seong YM, Lee WJ, et al. Case of the index patient who caused tertiary transmission of COVID19 infection in Korea: the application of lopinavir/ritonavir for the treatment of COVID-19 infected pneumonia monitored by quantitative RT-PCR. J Korean Med Sci 2020;35:1-6.

7. Diyy A ASM, Thomas NV. Potential therapeutic avenues for COVID-19 therapy. Int J Pharm Pharm Sci 2020;12:11-4.

8. Anand K, Ziebuhr J, Wadhwani P, Mesters JR, Hilgenfeld R. Coronavirus main proteinase (3CLpro) structure: basis for design of anti-SARS drugs. Science 2003;300:1763-7.

9. Chen YW, Yiu CP, Wong KY. Prediction of the SARS-CoV-2 (2019-nCoV) 3C-like protease (3CL pro) structure: virtual screening reveals velpatasvir, ledipasvir, and other drug repurposing candidates. F1000 Res 2020;9:1-17.

10. Zhang L, Lin D, Sun X, Curth U, Drosten C, Sauerhering L, et al. Crystal structure of SARS-CoV-2 main protease provides a basis for design of improved $\alpha$-ketoamide inhibitors. Science 2020;368:409-12.

11. Yan R, Zhang Y, Li Y, Xia L, Guo Y, Zhou Q. Structural basis for the recognition of SARS-CoV-2 by full-length human ACE2 Science 2020;367:1444-8.

12. Towler P, Staker B, Prasad SG, Menon S, Tang J, Parsons T, et al. ACE2 X-ray structures reveal a large hinge-bending motion important for inhibitor binding and catalysis. J Biol Chem 2004;279:17996-8007.

13. Maruta H. Herbal therapeutics that block the oncogenic kinase PAK1:a practical approach towards PAKAdependent diseases and longevity. Phytother Res 2014;28:656-72.

14. Vincent MJ, Bergeron E, Benjannet S, Erickson BR, Rollin PE, Ksiazek TG, et al. Chloroquine is a potent inhibitor of SARS coronavirus infection and spread. Virol J 2005;2:1-10.

15. Lu S, Strand KA, Mutryn MF, Tucker RM, Jolly AJ, Furgeson SB, et al. PTEN (Phosphatase and Tensin Homolog) Protects Against Ang II (Angiotensin II)-induced pathological vascular fibrosis and remodeling-brief report. Arterioscler Thromb Vasc Biol 2020;40:394-403.

16. Chen IY, Chang SC, Wu HY, Yu TC, Wei WC, Lin S, et al. Upregulation of the chemokine (CC motif) ligand 2 via a severe 
acute respiratory syndrome coronavirus spike-ACE2 signaling pathway. J Virol 2010;84:7703-12.

17. Kanjanasirirat P, Suksatu A, Manopwisedjaroen S, Munyoo B, Tuchinda P, Jearawuttanakul K, et al. High-content screening of thai medicinal plants reveals boesenbergia rotunda extract and its component panduratin a as anti-SARS-CoV-2 agents. Researchsquare 2020;10:1-22.

18. Cole JC, Murray CW, Nissink JW, Taylor RD, Taylor R Comparing protein-ligand docking programs is difficult. Prot Struct Func Bioinf 2005;60:325-32.

19. Trott O, Olson AJ. AutoDock Vina: improving the speed and accuracy of docking with a new scoring function, efficient optimization, and multithreading. J Comput Chem 2010;31:455-61.

20. Wallace AC, Laskowski RA, Thornton JM. LIGPLOT: a program to generate schematic diagrams of protein-ligand interactions. Protein Eng Des Sel 1995:8:127-34.

21. Flamandita D, Lischer K, Pratami DK, Aditama R, Sahlan M. Molecular docking analysis of podophyllotoxin derivatives in sulawesi propolis as potent inhibitors of protein kinases. AIP Conf Proc 2020;2230:020010.

22. Hsu MF, Kuo CJ, Chang KT, Chang HC, Chou CC, Ko TP, et al. Mechanism of the maturation process of SARS-CoV 3CL protease. J Biol Chem 2005;280:31257-66. 